\title{
CROSSING COREFERENCE IN DISCOURSE REPRESENTATION 'THEORY
}

\author{
Michal HESS \\ University of Zurich \\ Dept. of Computer Science, Winter thurerstr. 190 \\ CH-8057 Zurich, Switzerlatnd
}

\begin{abstract}
:
Scntences with crossing coreference (Bach-Peters-sentences) are notoriously difficult to explain in a natural manner. An intriguing paraliel with certain properties of Plolog suggests a modification to Discourse Representation Theory which allows a simple and coherent explanation of these, and related, sentences,
\end{abstract}

\section{The Problem}

In English there is one type of sentence that has caused major problems for practically all linfigistic theories that have tried to cxplain it, and none of the explamations put fortvard is very convincing. The sentenes in question are those with crossing cortference, the so-calted Bach-Peters-sentences. The standard examples are

1) The huster who shot at. it hit the lion that chased hin

and, with explicit guantifier expressions:

2) Every fian who wants it will get the prize ho deserves

What is the difficulty with this type of scntence? They contain two noun phrases each of which contains a pronoun that refers to the other noun phrase, and the first pronoun is furthemore a case of "backwards anaphora", or "calaphoril" These sentences arc admitledly rare, but sentences with simple (non-crossing) cataphora are quite frequent in real world English (Carden 1982). And BachPeters-sentences are nevertheless perfectly regular, and so they should find a natural explanation. Morcover, they are key cxamples of sentences where catat phora cannot, in principle, be replaced by anaphora (cf. also Mittwoch 1983) This is imporlant because one of the standard approaches to cataphora has becn to define it away as stylistic variant of anaphora, which can be "rectified" by a simple transposition. In other words: Since we have to find a way to explain cataphora for Bach-Peters-sentences anyway, we can save us the trouble to devise such tricks for the simpler cases.

\section{Are Bach-ll'eters-Pronouns Descriptional Pronouns?}

The non-reducibility of cataphoric to anaphoric pronouns in Bach-Peters. sentences becones clear if we try to explain them in the traditional manner. It secms that bott of the two traditional interpretations of pronouns, the "descrip tional" as well as the "denotational" one, fail to explain the intuitive truth conditions of Bach-l'eters-sentences. In Transformational Grammar the descriptional approach is taken, and pronouns are always expanded to the surface syntax form of the noun phrase they anaphorically refer to (in other words, pronominalization is an obligatory cyclic rule). But then we get, for the example above, a double infinite embedding of relative clauses:

The hunter who shot at

(the li.on that chased

(the hviter who shot at (the lion that chased ...))

hit the lion that chased

(the hunter who shot at

(the lion that chased

(the huntes who shot at ...)1)

This analysis is patently uselcss. Karttumen shows (Kartunen 1971) that dropping the requirement that pronominalization is a cyclic rule alleviates tlic problem somewhat, but at a cost: It would make sentence 1 derivable from (at least) two different decp structures, viz. from the deep structures corresponding to the sentences

3) The huntex who shot at the lion thit chased him hit it.

4) I'he lifon that chased the hunter who shot at it was hit by hin

This would mean that 1 has to be ambiguous between the meanings of 3 and 4 . 'I'his is what Kartumen assumes, but it is a highly dubious claim as Karttunen himself seems to feel (Kartunen 1971:167 f.). Moreover, the structute of 1 could also be derived from a deep structure corresponding to

5) The hunter who shot at the lion hit the lion that chased the hunter:

But this sentence is considered by matny informants to be simply ungrammatical (Kattunen 1971:178), and it is not acceptable at all under the coreference relations that should oblain between the noun phrases. Finally, the assumption that 1 is three ways ambignous between 3,4 and 5 is untcceptable, too. In order to show this, and in order to understand better what these three sentences really mean, we can use a set of data bases (after Karttunen 1971) which cither contain, or do not contain, well-defined referents for the various definite noun phrases oceuring in the example sentences. We will see that 1 is not ambiguous between 3 and 4 , but that the three sentences have three distinct meanings which can be derived directly from their syntactic structure. This proves, at the same time, that cataphoric pronouns are irreducible in Bach-Pelers-sentences. Let us first comsider the definite noun phutse "the hunter who shot at the lion that chased him" (from 3) consisting of an embedding of two definite noun phrases. Since each singular definite noun phrase presupposes that there is a nnicue referent for it, this phrase can refer to a pair "henter $\mathrm{H}$ - lion $\mathrm{L}$ " in the case where lion $\mathrm{L}$ is the only lion chasing hunter $\mathrm{H}$, and this hunter $\mathrm{H}$ shot at this very lion $\mathrm{L}$. In the fol lowing data base (Kattunen 1971:166) there is one such pait.

hunter (hi).

hunter (h2).

hunter (h3)

shot:at: $(11,1,1)$.

shot: at. $(h 1,13)$

For alch humer, there is a single lion chasing bim but only ous funter also shoots at this lion, viz, hunter 2 who shoots at lion 3. Hunter 2 shools at other lions, as well (e.g. at lion 1) but lion 1 doesn't chase hunter 2 (although it does chase other hunters, e.g. hunter 3). Hence it can be sitid (Dik 1973:320) that the definite aoun phrase "the hunter who shot at the lion that chased him" has a well-defined referent in any data base which contains just one configuration of the lype

6)

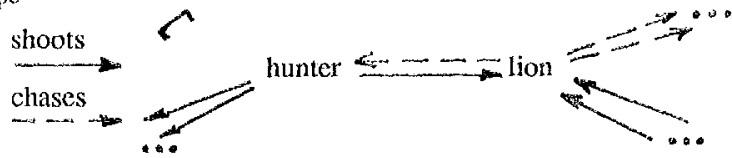

This rules ont that other lions chase the hunter, but it leaves open the possibility that the hunter shoots at other lions, that the lion chases other lunters and, in par ticular, that other hunters shoot at the lion. On the other land, example 4, "The lion that chased the hunter who shot at it was hit by him", is not interpretable in the data base given above. Its subject, "the lion that chased the hunter who shot at it", fails to refer properly: There is only one lion for which there is a hunter we can call "the hunter who shot at it", vir. lion 2 (the other two lions are both being shot at by more than one hunter), but lion 2 does not chase "the hunter who shot at it" (viz. hunter 3), and so the entice noun phrase fails to refer. $A$ data base where there is a referent for this noun phrase could look like that:

hunter (h:1)

hunter (h2).

hunter (h3)

shot at (hil, 12)

chased $(11, h 1)$

chased $(1.1, \mathrm{~h} 3)$.

chased $(12, h 1)$. Li.on(13)

$\operatorname{lion}(11)$

lion (12).

chat at (h2,11) chased $(13, \mathrm{~h} 2)$

The definite noun phrase "the lion that chased the hunter who shot at it" has a well-clefined referent in any data base which contains just one configuration of the type 7:

7)

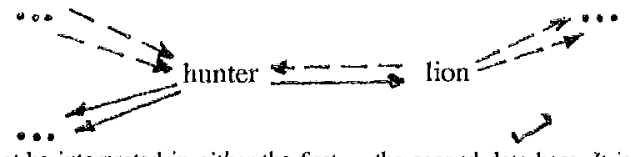

Example 1 cannot be interpreted in either the first or the second data base. It is interpretable only in a data base which contains at most onc configuration like 8 which combines restrictions 6 and 7 : 
8)

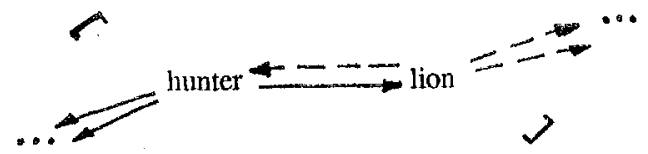

\section{Are Bach-Peters-Pronouns "Bound Variable" Pronouns?}

Since the unmodified as weil as the modified descriptional interpretations of pronouns in Bach-Peters-sentences do not allow us to represent these distinctions they cannot be accepted. But how do the "deep" approaches to pronouns, the socalled "denotational" interprctations, fare?

The prototypical denotational interpretation of pronouns is the one suggested by First Order Logic, where bound variables are seen as the logical counterpart of pronouns in Natural Language. If we use iota-operators, we could try to translate 1 into

9) hit (iota $Z$ : [hunter $(Z) \wedge$ shot at $(Z, W)$ ],

iota $W:[$ lion $(W) \wedge \operatorname{chased}(W, Z)])$

The trouble is that iota-operators bind their variables, making them inaccessible for reference from the outside. Hence we cannot refer forward from the term "shot_at $(Z, W)$ " to the "W" in the second iota-expression, nor can we refer backward from "chased(W, $Z$ " to the " $Z$ " in the first iota-expression. If we add equality to First Order Logic there is a way out. We could re-phrase 9 as

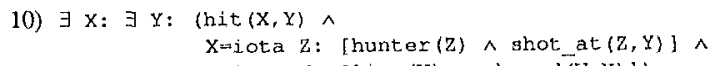

The other examples, 3 and 4, would then become

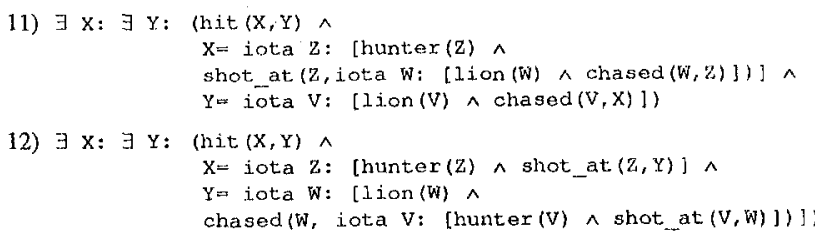

But in cases 11 and 12 part of the expression must be repeated, namely the one stating the uniqueness of the hunter-chasing lion, and of the lion-shooting hunter, respectively. This is a very unattractive way to express this sort of thing, and Karttunen agrees: "One is tempted to think that one of [these repeated definite descriptions] could be eliminated by a more clever use of variables, especially when variables in predicate calculus are generally used very much the same way as pronouns in natural language. [...] [But] the second appearance of the same description cannot be avoided, because, in predicate calculus, theic is no way to refer back to the first." (Karttunen 1971:176).

\section{McCawley's suggestion: Referential indices}

But this is the point where other people disagree. McCawley (McCawley 1970), for instance, argues (for other reasons), that the semantic represcntation of sentences should not be cast in terms of First Order Logic, but tather in terms of the overall proposition of a sentence plus referential indices. The proposition would define the relationship that exists between the different objects talked about in the sentence, but these objects would be represented independently by referential indices that correspond to the "intended reference" of the noun phrase. These indices are "identified" by the noun phrases in the sentence, i.e. their values are determined by the noun phrases. A sentence such as "The man killed the woman", would be translated as

13) $s($

proposition (killed $(\mathrm{x} 1, \mathrm{x} 2))$,

np (X1: the man)

np (X2: the woman))

A surface sentence would be generated from this structure by replacing the referential indices in the proposition by the noun phrases identifying them. As for Bach-Peters-sentences, example 1 would be represented as

14) si

proposition (hit (X1, X2))

np (X1: the huntex who shot at $X 2)$

np (X2: the lion that chased X1))
Here the referential indices are identified by noun phrases which themselves contain referential indices. If we want to generate a surface sentence from this structure we will have to replace the referential indices by their identifying noun phrases, but we will not be able to replace systematically all referential indices this way, because this would lead to the same kind of infinite embedding that we encountered above. We will rather, ai some point in the derivation, lave to turn some of the referential indices into pronouns (taking into account case, gender and number). The point at which we stop replacing referential indices by full noun phrases and start turning them into pronouss witl deternine which of scveral possible paraphrases of a sentence we will obtain. The distinction between "proposition" on the one hard and "xeferential index" with the accompanying "identifying noun phrase" on the other hand allows MeCawley to overcome the problem with repeated components: The "identifying nom phrase" of a referential iudex is mentioned only once, independently of how many times the referential index itself is used elsewhere in the representation.

\section{Dik's Modification of MeCawley's 'Theoly}

This approach las been criticized on different counts. First, it is not cleax at which point relerential indices may beg in to be turned ino pronouns rather than being replaced by identifying expressions. Second, and more importantly, McCawley's suggestion allows all three sentences $(1,3$, and 4) to be derived from the same scmantic representation, which would require that they are all synonymous. Hence, all the problems we encountered with the descriptional interprotation of pronouns are back with a vengeance. Does that mean that we have to return to the standard First Order Logic representation with all its unatractive features (repetition of components)? Dik 1973 suggests a modification of McCawley's approach that takes care of the empirical fact that the three sentences mentioned above are not synonymous.

The main syntactic difference between the threc example serttences is the way in which the different full noun phtases are enibedded in each other. In particular, in the Bach-Peters-sentence there are no embedded full noun phrases; the only embedded noun phrases are pronouns ("who shot at $i t^{\prime \prime}$ " that chased him"). This kind of distinction is lost in McCawley's original notation, which is the reason why he has to claim that the examples sentences are all synonyrnous. Dik's first (and main) modification of McCawley's notation makes sure that this, crucial, distinction is not lost. The way to achicve this goal is by iniroducing what might be called (not Dik's expression) "annotated variables" to take the place of McCawley's referential indices, which are constants. The annotation of a variable indicates how the value of the variable is to be computed. Thus "X2(X2=iota $Z$ : (lion $(Z) \wedge$ chased $(Z, Y))$ )" is an amotated variable. This would give us, for 3

15) hit $(X 1, \times 2)$

$$
\begin{aligned}
& X 1=\text { iota } Y:(\text { hunter }(Y) \wedge \\
& \text { shot_at }(Y, X Z\{X Z \text { Lota } Z:(J i o n(Z) \wedge \operatorname{chased}(Z, Y)\rangle)))
\end{aligned}
$$

As in McCawley's system, referential indices must be replaced by the corresponding identifying expressions, and any variables remaining after this step are turned into pronouns. In addition, we have the usual convention that functional expressions are to be evaluated from the inside out. But what is gained by faithfully copying a certain syntactic structure (viz. embedding) into the deep representation? Are the interpretation rules given by Dik really sufficient to interpret the resulting expressions correctly? If we jerform the replacement, for instance, in 15 we get

16) hit (iota $Y:$ (hunter $(Y) \wedge$

shot_at $(Y, X 2(X 2=$ iota $Z:(1$ ion $(Z) \wedge \operatorname{chased}(Z, Y)))), X 2)$

Now, if we wanted to gencratc a surfacc sentence from this representation we would turn the remaining unbound variable, i.e. " $\mathrm{X} 2$ ", into a pronoun, and everything would be in order. But what if we wanted to evaluate this statement over one of the data bases? The X2 on the level of the proposition, i.e. "hit(..,X2)" is clearly outside the scope of the "annotation" defining its value, and so we would expect it to remain unbound after the annotation itself has been evaluated. This is, after all, precisely the reason why Karttunen thought it necessary to reintroduce the duplication of logical expressions that McCawley had tiicd to get rid of: To provide the second, outer, occurrence of this variable with a value. We need an interpretation rule which specifies how variables of this kind can be bound, and this rule is not provided by Dik. 


\section{An Unexpectedly Simple Solution Suggested by Second- Order Prolog Constructs}

As it tums ont, the additional interpretation rule that makes the correct interpretation of Bach-Pcters-sentences virtually "fall out" is the definition of second-order operators, and ithe general interpretation rules of Hom Clause Logic, as implementcd in stantard Prolog: Instead of " $Z=i o t a X:(Y)^{\text {"1 }}$ we use "setof $(X, Y,[Z])$ ", where the unicueness requiremest is built into the definition of "setof", and singularity is enforced by requiring the result list to consist of exactly one elemont. Annotated variables on the other hand are "multiplied ont" in the relational spirit of Prolog, i.e. insteal of "predicate(X, $Y(X=Z))$ " we write "(predicate $(X, Y), Y=Z)$ ). Combining these two steps we get, for the expression above,

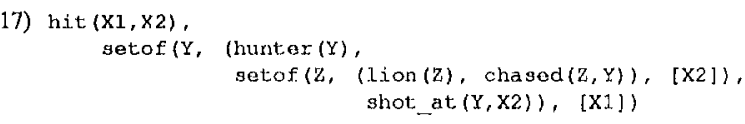

or, with a more suggestive choice of variable names and a more efficient ordering of the goals

$$
\begin{aligned}
& \text { 18) setof ( } \mathrm{H} \text {, (hunter (II), shot at ( } \mathrm{H}, \mathrm{C} \mathrm{C} .) \text {, } \\
& \text { hit: (TH, TL). } \\
& \operatorname{set} \text { of }(L,(\operatorname{lion}(L), \operatorname{chased}(L, T H)),[T L])),[T H]) \text {, }
\end{aligned}
$$

Now the desiret truth conditions come out correctly. We can see this if we treat 18 as a Prolog (query: We find, first, a hunter ("H") who shoots at something ("TL"). Then wis check whether this entity is identical with the set of exactly onc lion ("[TL]") that chases someone ("TH") who must then turn out to be identical with the hunter who is the only such hunter ("[TH]"). Finally we check whether this hunter also hits this lion. The other sentences arc represented the same way: 4 and 1 (the Balch-Peters-sentence) give

19) setof (L, (1ion (L), chased (L, 'III), hit $(T H, T C)$.

$$
\text { setof(H, (hunter(H), shot_at }(H, T L)),[T H])),[T L]) \text {, }
$$

20) setof(H, (hunter (H), shot_at $(\mathrm{H}, \mathrm{TI})),[\mathrm{TH}]$ ) setof $\left(I_{1},\left(\right.\right.$ lion $(L)$, chased $\left.\left.\left(I_{r}, T H\right)\right),\left[T^{\prime} L\right]\right)$. hit $(\mathrm{TH}, \mathrm{T} \mathrm{C})$.

Now we get, without any additional stipulations, the three different interpretations for the the example sentences. The sentences are neither collapsed into one single mearing representation (with three synonymous surface sentences), as with McCawley's approach, nor into two different ones (with two distinct and unambiguous, and one ambiguous, surface sentence), as with Karttunen's approach. The simple fact that in Bach-Pcters-sentences the full definite descriptions are not eribedded, forces them to cvaluate to two distinct, independently unique, values, and this ensures that these sentences are true only over data bases meeting condition 8 .

But how can this unexpectedly straightforward solution be explained? The main problem that McCawley's representation, and Dik's modification of it, tried to overcome was: How can variable values be communicated into iota-expressions from the outside, despite the fact that, in First Order Logic, variables within the scope of an operator or quantifier are shielded from the outside? Now, in Horn Clause Logic all variables of a clause are, implicitly, universally quantified (which means that variables in a query, i.c. in a negated clause, are existentially quantified), and the scope of the implicit quantifiers is the entire clause. The bindings of variables "spread" throughout the clausc, irrespective of how deep a variable may be embedded. This also applies to the setof-operator: All its variables are accessible from the outside, within the given clause. The variables can, of course, still be unbound when the evaluation of the setof-expression begins, and then it is the evaluation of the setof-expression that will establish bindings for these variables. But they can also get bound elsewherc, before the operator is used, and "spreat forward". And then a proof of the setof-expression treats these pre-established bindings as constraints to be satisfied. This is the Prolog way to implement the cataphoric pronoun in Bach-Peters-sentences. In this, last, respect the setof-operator in Prolog is treated as just another predicate, and its being second order is irrelevant. The difference is that the interpretation of the setof operator uses Prolog's meta-call facility. Or, to put it differently: A piece of code (the entries in the second argument of the setof-operator) is first treated as "data" (variable bindings are communicated with the outside world), and then it is treated as a piece of "program" that is executed (using the variable bindings that are established at this point in time). And in this the Prolog setof-operator differs fundamentally from the iota-operator as used in First Order Logic. The iotaoperator has, at far as variable binding is concerned, the same force as a quantifier: A variable in its scope is immune from any outside interference.
Now it is clear why we need not repeat any expressions in the representation of the example sentences, and yet the variables all get properly bound: In the example above, the two terms of 18 (i.e. the setof-expression and the expression "hit(TH,TL)") are part of the same clause, and values for variables created in either of them will spread to the other. In particular, the value which the variable "TL" takes during the evaluation of "shot_at(H,TL)" is still available during the evaluation of the embedded "setof $(L,(\operatorname{lion}(L)$, chased $(L, T H)),[T L])$ ", and later during the evaluation of "hit(TH,TL)".

\section{Mapping Variables onto Pronouns}

If we want to generate surface sentences from these structures, we must distinguish between two uses of variables: First there are those uses which are merely an artefact of the relational way of representing functional application, and, second, there are those that correspond to true anaphoric relations in language. The first use is simple: If we want to represent functional applications such as

\section{plus(times $(3,2), 4)$}

in a relational language, we must "multiply out" the embedded expression and create auxiliary variables for the intermediate results, c.g. " $\mathrm{X}$ " and " $\mathrm{Y}$ " in

times $(3,2, X), \operatorname{plus}(X, 4, Y)$

Thus we had to use 20, with auxiliary variables "rH" and "TL", instead of a functional representation such as, for instance,

21) hit (set (H, (hunter (H), shot at $(\mathrm{H}, L))$ ), set $(\mathrm{L},(1$ ion $(\mathrm{L})$, chased $(\mathrm{L}, \mathrm{H})))\}$

These "auxiliary" variables are situated on the same level of cmbedding (by definition: their purpose is to flatten embeddings). Co-occurrence of such vatriables on the same level of embedding naps, in simple cases, onto concatenation ("A") in surface structure: Thus the following occurrences of variables "TL" and "T'FI" in 20

20a) setof $(L,(\ldots), T L])$, setof $(H,(\ldots),[\mathrm{TH}])$ hit $(\mathrm{TH}, \mathrm{TL})$.

become $"\left((\text { the hunter })^{\wedge}\right.$ hit ${ }^{\wedge}$ (the lion) $) "$. Co-occurrence of variables across different levels of embedding, however, cannot be encoded as simple concatenation. These cross-references map onto pronouns. (The converse does not hold: There are pronouns that do not correspond to this kind of cross-reference; c.g. descriptional pronouns.) Thus the level-crossing co-occurrence of the variable "TL" in

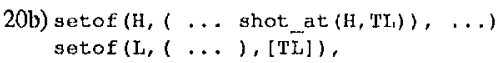

must map onto a pronoun ("The hunter who shot at $i$ "). A problem arises when we try to translate 19 back into English. If we begin the translation process with "hit(TH,TL)" and map the level-crossing variable "TH" onto a pronoun we get "He hit the lion that chased the hunter who shot at it", which is not acceptable under the intended interpretation (i.c. coreferentiality of "he" and "the hunter ..."). This corresponds to a well-known syntactic restriction on the use of cataphoric pronouns. Here we need a rule that works for syntax generation rather than for analysis. The following rule is a bit ad-hoc, but it is sufficient for the present purpose: We require that the translation of the entire set of expressions must begin with the expression defining the top relationship between the individual set expressions (i.e. with the expression corresponding, in most cases, to the main verb of the surface sentence), and that level-crossing occurrences of variables in this term are translated last. If this restriction makes it impossible to translate these variables from, say, left to right (as in the case of example 19 where the first variable "TH" is a level-crossing occurrence), it is done right to left. This requires that the surface verb form is passivized but it gives the grammatically correct ordering of full noun phrases and pronouns (i.c. we get the original passive sentence 4 for 19). In Bach-Peters-sentences such as 20 both the active and passive versions are admissible under this restriction, in keeping with the linguistic facts. 


\section{Second-Order Prolog Constructs and Discourse Represen- tation Theory}

The painless way in which the correct truth conditions of Bach-Peters-sentences and the rclated sentences virtually fall out of the standard Prolog interpretation rules and the definition of the second-order setof-operator is not just a lucky coincidence. It is rather another case of the intriguing parallel between Natural Language and Horn Clause Logic which has become particularly clear in Discourse Representation Theory (DRT). The main hypothesis of DRT is that noun phrases (and articles) have no quantificational force on their own but are implicitly quantified by the context. This allows DRT to explain, with remarkable ease, so-called donkey-sentences, a type of sentence that does not yicld to the traditional interpretation of noun phrases as quantified statements. The correspondence between the logic underlying DRT, and Horn Clausc Logic is, in this respect, almost one-to-one: In DRT, (indefinitc) noun phrases introduce discourse referents which are quantificd by the (discourse) context in the same way as variables in Horn Clause Logic are implicitly quantificd by the (clause) context.

How do Bach-Peters-sentences fit into DRT? First, we notice the paralle between McCawley's ideas and DRT: His "referential indices" correspond, in their intended function, to the discourse referents in DRT, and "propositions" correspond to the DRT "conditions" on discourse referents. In the Prolog version of Dik's modification of McCawley's ideas, discourse referents correspond to the value of the third argument in a sctof-operator, and the "conditions" of a Discourse Representation Structure (DRS) to the expression(s) in its second argument. All this applies, for the time being, only to definite noun phrases and their representation. If we want to incorporate this into DRT, we must first provide for the possiblity to explicitly represent the embedding of noun phrases. This kind of explicit embedding was the main reason why we got the right truth conditions in the Prolog representation of the example sentences. We must, in other words, be altowed to use embedded "conditions" in a DRS. Traditional DRT allows for the embedding of entire DRSs, but not of individual conditions. While a sentence like "If John owns a donkey that dislikes him, he beats it" is traditionally rejresented as a flat DRS like

22) [u1:

[u2: john(u1), donkey (u2), owns(u1,u2), dislikes(u2,u1)] $\rightarrow$ beats $(u 1, u 2)]]$

(cf. Kamp 1981, Kamp 1983, Frey 1983, Guenthner 1983, Guenthner 1985, Kolb 1985, Guenthner 1986, Pinkal 1986, Root 1986) this will not do for the sentences with embedded definite noun phrases considered above. We must somchow represent this embedding. And we must, obviously, provide for the interpretation rules to use them. These rules will crucially rely on Prolog's meta-call facility to implement the double use of ernbedded set-expressions, as data structures on the one hand and as "executable procedures" (i.c. as provable assertions) on the other.

In traditional DRT mostly indefinite and universal noun phrases (and proper names) are used while the Bach-Peters-sentences considered above all contained definite noun phrases. But for some of them there are versions with indefinite noun phrases, too, and all of them have corresponding plural versions. In order to cover all these cases we must introduce, instead of the "conditions" of DRT, generalised set expressions without the totality implication of Prolog's "setof" (cf. also Webber 1983). We use "set(Def,Card,Gdr,Var,Int,Ext)", where "Def" can take the values "def"(inite) or "indef"(inite), and "Card" either an explicil number, "plur", or a quantifying expression ("all", "some" etc.). "Gdr" gives the gender of the main noun. "Var"(iable),"Int"(ension) and "Ext"(ension) correspond to the three arguments of the setof-operator. The variable "Ext" can now stand for sets as well as for individuals.

\section{Mapping Pronouns onto Variables}

So far we have mentioned how pronouns correspond, statically, to certain semantic objects of our modified DRSs (i.e. to the level-crossing occurrences of variables). But it is one of the main goals of DRT to give a unified account of what the procedures that actually perform the resolution of pronouns should look like. This problem is much harder than the converse one, i.e. the mapping of levelcrossing variables onto pronouns. The central idea used here by DRT is simple (it gocs back to Karttunen, together with the term "discourse referent"): Indefinite noun phrases in "assertive" contexts create discourse referents which "live on", and which can be accessed by anaphoric expressions from points later in the sentence or discourse. Discourse referents, however, that are created by indefinites in universal, conditional, and negative contexts, "die off" when the sentence in which they occur is processed. This idea corresponds closely to Prolog's concept of variables and Skolem constants (the latter standing for existentially quantified variables): During the interpretation of a program variables remain accessible $b y$ name within the clause where they occur. This corresponds to the limited lifespan of discourse referents created in universal, conditional, and negative con- texts. For Skolem constants in Prolog, however, the scope is the entire program; they "live forever", in the same way as discourse referents created by indefinites in assertive contexts. And whenever a (definite) pronoun or definite noun phrase is encountered, a suitable antecedent must be located among the discourso referents still "alive". Its value is then replaced by the value of the discourse referent found. If several pronouns access the same discourse referent, they get, of course, the same value. This is the DRT counterpart of unification.

If we want to have, in our modified notation, discourse referents "float on the surface" of the corresponding DRSs, accessible for later anaphoric reference, we could write, for the indefinite version of 3 , viz.. "A hunter who shot at a lion that chased him hit it"

19a) [TL, TH: set (indef, 1 , masc, $H$, (hunter $(H)$, shot at $(H, T L)$ set (indef, 1 , neutr, $L,(1$ ion $(L), \operatorname{chased}(L, I H)), T L)$, TH) hit. $(T H, T J)]$

But there are fundamental differences between the treatment of variables in Prolog and DRT: During the interprctation of a Prolog program, bindings of a given variable spread throughout a clause to all occurrences of the same name, forwards and backwards. DRT, however, allows only forwards, "anaphoric", spreading of values. Since a pronoun is processed as soon as it is encountered, it can "look for" antecedents exclusively in the DRSs built up by the preceding discourse. The interpretation procedures of DRT thus implement, implicitly, the syntactic rule that a pronoun can refer anaphorically to a preceding noun phrase that $c$-commands it. Because this is, at the same time, the only case where anaphora is allowed, these interpretation rules block, correctly, cataphora from the pronoun to the indefinite noun phrase in

23) He said that a boy had taken the book

But legitimate cases of cataphora, such as those in Bach-Petcrs-sentences, are blocked by these intcrprctation rules of DRT, as well. Hence we must weaken the accessibility restrictions for anaphoric pronominal references somewhat, but not too much: If we modelled them on Prolog's unrestricted variable sharing, 23 would go through in its coreferential reading.

Accessibility rules of DRT not only block certain correct interpretations, they also allow certain blatantly incorrect ones. They would allow, for instance, the sentence above with a definite noun phrase, i.c.

24) He saj.d that the boy had taken the book

to get an interpretation where pronoun and definite noun phrases are coreferentiai. Why? The correct interpretation of this sentence (no coreference between "he" and "the boy") requires that the definite noun phrase will be able to find an antecedent among the pre-existing discourse referents. But then the sentenceinitial "he" would be equally capable of accessing them, and this would allow the prohibited coreferential, cataphoric, reading of the "he" (i.e. "pseudo-cataphora" via a common antecedent). The same thing holds for "He hit the lion that chased the hunter who shot at it".

The prohibited reading of this type of sentence can be ruled out on the basis of purely syntactic information. The standard rule about pronouns says that a pronoun cannot be coreferential with an noun phrase if it both precedes and ccommands it. This rules out the cataphoric use of a pronoun if it c-commands its target noun phrase but it allows cases of cataphora such as

25) When he got up, John felt hungry

(which are reducible to anaphora) as well as Bach-Peters-sentences (which are not), but it blocks the prohibited coreferences in "He hit the lion that chased the hunter who shot at it" and "He said that the boy had taken the book".

Mittwoch (1983) has shown that these purely syntactic criteria are not sufficiently general to cover all relevant occurrences of cataphora. In many cases, discourse considerations are needed to explain why cataphora is allowed. The pronoun can occur, for instance, in a sentential constituent which is demoted, by explicit discourse subordination markers, to a lower position than warranted by syntax. Thus, in

26) I haven't seen him yet but John is back

(from Mittwoch 1983) the "but" functions as an overt marker of topicality for the second sentence, demoting the first sentence, and in

27) He may not represent the us at the United Nations anymore, but that does not mean that Andrew Young has slowed his pace 
(from Macleod 1984, gtotingy from "Tinc") the "but", together with the modal "may", even matuages to make calaphora acceptable from a sentence initiat sub ject position (at least in journalesc). The common element of alf these examples of cataphoric pronouns is that they occur in discourse conditions. Yn simple cases this coincides wilh scritential conditions ("if" etc.), and very often with subsentential conditions (in pauticular with postmodificers of noun phrases, such as restrictive relative clanses, prepositional phrases, or nonfinile clauses). Thut the picture is complicated by the fact that the "antecelent" of cataphoral imist be definite if the searence is spectific. Contyare

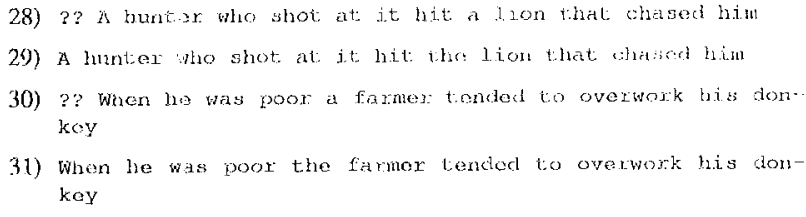

In general (and in many sencric) sentences this restriction does not hokt. The following sentences are fine although the "antecedent" noun phases we indefinite:

32) A kunter who shoots at it witl. hit. a lion that chates him

33) Tf ho is roos: a farmer will tond to overwork his donkey

What secirs to lappen here is that, intutively speaking, the cataphoric pronour sels ity an "conectation" for a following noun phrase which is specific of nonspecific, depending on the specificity of the conditonit context in which the pro noun finds itself 'ithe specilteity of the pronominal context is deteminch (mainly) by the aspeet of the verb there: "who shoots" vs. "who shot", "if lic is poor" vs. "when he was poor", etc. A specific expectation requires a definte noun pluase or a proper nante as its "antecedent", while a tron-specific one accepts either au indefinite or a déinite noun phanse.

\section{Required Modlifications to Discourse Representation 'Theory}

How could DRT incorporate this kind of information in order to determine more teliably the range of pemissible anaphora and cataphora, while ruling out the illegal coreferential reading in sentences like "He said that the boy lad taken the book"? "The following is a list of requirements for an implenentation that would take these additional conditions into account: As in traditional 1$) R$ ' $\mathrm{l}$, the incom ing sentence opens a ncw DlRS, which defines the space where all newly created discourse referents can survive. Noun phrases create set expressions (the "conditions" of standard heory): Indefinite and definite noum phases give rise to normal set expressions, while pronouns create set expressions of a special type Indeftnite noun phrases give rise, in addition, to discourse referents, which are deposited in the DRS under construction. Traditional DRT has proper names create discoutse referents, too. Whether this is the best possible decision is open to debate. It would, in many respects, be more consistent to treat proper names on a par with definite noun phrases. Discourse reterents should contain all the information that can become relevant for the resolution of pronominal andaliora, i.e. at least number and gender. Definite set expressions derived from full noun phrases without conditional modifiers, as well as those derived fiom definte pronouns, are craluatrid as soon as they are created, i.c. they try to find their antecedents among the pre existing discourse referents. Expressions for pronoun whose autecedents have been found ate removed, once they have done their duty ats value sharing chinncks. So far nothing really new.

But now the first nodification of standard theory is nexded: Definite full noum phrases are not allowed to look for then antecedents inside the DRS still under construction, whereas pronones may do so. Second, when any definite noun phrase (full noun phrase or pronoun) has found the correct discourse referent, it drags it into the DRS under construction. 'These two changes make sure that two full nom phrases within the same clause are never interpreted as coreferential. 'They also block calaphora in "le said that a boy lat taken the book" (the "loe" las dragget the appropriate discourse referent into the IDRS, where it is "invisible" to the subsequent "the boy"). And, finally, it brings a discoutse referent accessed by a defiritie rotu phrase into focus and makes it the prime candiate for subseguent anaphoric icference by pronouns. The third modification to standare DR'T is this: Becents pronoms in nongeneric contexts requite definite nou phrases as antecedents (see examples 28 to 31 ), disonse refereuts must also catsy information about the definieness of the noun phase from which they were derived. Set expressions derived from pronouns will ase this information to detcrinine whather a given discourse referent is a possible antecedent. T'he fourth modification, finally, takes care of cataphora: Whenever an expression denoting a condition (on the discourse, sentence, or sub-sentential level) is encountered, no embedded DRSs are created (as it is done in standard DR'1 for "if"- and "cvery"sentences) and the production of discourse referents goes on, but evaluation of all new set expressions is suspended. In particular, no further attempts at anaphora resolution ate made, and all pronouns encountered from now on are stored in the DRS under constumetion as unevaluated set expressions. It is only when the end of the clause is reached that unevaluated set expressions are processed. Among the set expressions and discourse referents "in suspended animation" within a JRS, any reference (backwards and forwards) is permitted, as long as the conditions outlind atrove are fullilled. This allows cataphora to be modelled, while the classicil syutactic restrictions (calaphora only from a non c-commanding constituent) ate subsumed. Lastly, those discourse referents that are allowed to live (those from assetive, i.e. non-conditional, contexts, and those that were (ratged in from lic outside) are released into the universe of discourse referents.

ACI. 1983.

ACL, 1983, Proceedings of the 21st Annual Meeting of the ACL.

Brady 1983. Braty, M. and, R.C. Berwick, cd, Computational Models of Discourse, (The MIT Press Series in Artificial Intelligence), MIT Press, Cambridge, Mass./ London (1983),

Carden 198\%. Carden, (s., "Backwards anaphora in discourse content," Journal of Linguisticis 18 pp. 361-387 (1982)

Dik L973. Dik, S.C., "Crossing Coreference Again," Foundations of Language! J). 306-326 (1973).

[irey 1983. Firey, W. and Reyle, U., "Isxical I'unctional Gianmar and biskurstepräsentationstheoric als Grundlagen eines sprachverabeitenden Systems," Linguistische Berichte, (88) pl). 79. 100 (1983).

Gronendijk 1981. Croenendijk, J.A.G., Janssen, T.M.V., and Stok, M.B.J formal Methods in the Sudy of Naturat Language; Pari l, Mathematisch Centum Tract 135, Ansterdan (1981).

Guenther 1983. Guenther, $\mathrm{H}$. and Lehmann, HI., "Rules for Pronominalization," in: Procecdings of the 1st Conterence of the Eurojean Chapter of the ACL, Association for Computational I.inguistics, Pisa (September 1983).

Guenthner 1985. Guenther, I", "Linguistic Meaning in Discoutse Representation Theory," FNS-Bericht 85-5, Forschungsstelle für natiorlich-sprachliche Systeme, Universität J'ibingen (1985).

Guenthner 1986. Guenthner, F., Lehmann, H., and Schönfeld, $W ., " \Lambda$ theory for the representation of knowledge," $W B M$ of kes Develop? 30(1) pp. 39-56(1986).

Jacobs $1970 . \quad J a c o b s, R, A$, and , Roscnbaum P.S., cds., Readings in English iransformational grammar. 1970.

Kamp 1981. Kamp, H., "A 'Theory of 'Truth and Semantic Representation," pp. 277-322 in Groenendijk 1987, (1981).

Kamp 1983. Kamp, H., SHD withour Time or Questions, Unpublished; strongly runoured to appear as CSL R Report 1983.

Kartunen 1971. Karttunen, L., "Definite Descriptions with Crossing Coreference," Foundations of Language 7 p). 157.-182 (1971).

Kolb 1985. Kolb, H.-P., “Asplekte der Implementation der Diskursrepräsentationstheoric," FNS-Script 85-1, Universitäl T'übingen, Forschungsstelle filt natïrlichsprachliche Systeme (May 1985).

Macleod 1984. Macleod, N., "More on backward anaphora and discourse structure," J of Pragmatics 8 pp. 321-327 (1984).

McCawley 1970. McCawley, J.D., "Where do noun phrases come from?," pp. $166-183$ in Jacolss 1970, (1970).

Mittwoch 1983. Mittwoch, A., "Backwards Anaphora and Discourse Structure," I of Pragmatics 7 pp. 129-139 (1983)

Pinkal 1986. Pinkal, M., "Situationssemantik und Diskursreprassentationstheoric; Linordnung und Anwentungsaspekte," pp. 397-407 in Stoyan 1986, (1986).

Ront 1986. Root, R., "The Semantics of Araphora in Discourse," l'h.D. Thesis, Universitat Tübingen, Forschungsstelle fiir natirlichsprachliche Systeme, University of Texas at Ausin (May 1986).

Stoyan 1986. Stoyan, H. cd., GWAl 1986; 9th (erman Workshop on Artificial Intelligence, (Informatik-lachberichtc), Springer, Berlin cte. (1986).

Webber 1983. Webber, B.L., "So What Can We Talk About Now?," pp. 331-371 in Brady 1983, (1983). 